\title{
Role of Some Adipokines in Nonalcoholic Fatty Liver Diseases
}

\author{
Soha S. Zakaria*, Hala E. Hamouda*, Saber A. Ismail**, \\ Wael W. Mayah** and Mahmoud A. Keder** \\ Departments, of Medical Biochemistry*, Tropical Medicine **, \\ Faculty of Medicine, Tanta University, Egypt
}

\begin{abstract}
Background: The prevalence of non-alcoholic fatty liver disease (NAFLD) is increasing dramatically. It is unclear why some patients develop steatohepatitis, fibrosis and cirrhosis from steatosis, while others do not. A role for adipokines has been claimed. Aim of the Study: Evaluation of serum levels of leptin, soluble leptin receptor (sOB-R), TNF- $\alpha$, adiponectin and insulin resistance (IR) in cases of NAFLD, and to clarify their potential role in disease progression. Subjects and Methods: The study included 60 individuals, who were divided into three equal groups; group I: Normal healthy volunteers (control subjects) with BMI $\left(\mathrm{Kg} / \mathrm{m}^{2}\right)$ of $25.2 \pm 2.6$; group II: Obese individuals with fatty infiltration of the liver and having normal liver

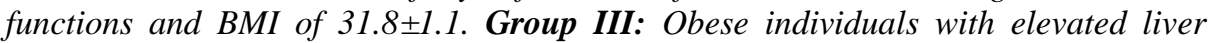
functions and BMI of $32.7 \pm 1.4$. All groups were subjected to estimation of liver function tests, lipid profile, fasting blood glucose level, HBsAg, HCVAb and evaluation of body mass index (BMI). Serum levels of insulin, leptin, soluble leptin receptor (sOB-R), TNF - $\alpha$, and adiponectin were measured in all groups using ELISA technique. IR was estimated by homeostasis model assessment index ratio (HOMA$I R)$. Results: Serum triglycerides, insulin and HOMA-IR were significantly increased in the patients' groups, when compared to the control group. Serum levels of ALT, AST, leptin and TNF- $\alpha$ were significantly increased, while $S O B-R$ and serum adiponectin levels were significantly decreased in group III compared to groups I and II. Serum leptin and TNF- $\alpha$ levels were positively correlated with BMI and HOMA-IR in groups II \& III and with serum ALT and AST enzyme activity in group III, while, sOB-R levels were negatively correlated with serum leptin, TNF- $\alpha$, BMI and HOMAIR in both patients' groups and with ALT and AST enzyme activity in group III. On the contrary, serum adiponectin levels were negatively correlated with BMI and HOMA-IR, serum leptin and TNF- $\alpha$ levels in groups II \& III and with both ALT and AST enzyme activity in group III. Conclusion: Measurement of serum TNF- $\alpha$, serum leptin and/or adiponectin may be helpful biochemical markers of NAFLD, particularly when serum AST and ALT are within normal limits.

Key Words: Nonalcoholic fatty liver disease (NAFLD), soluble leptin receptor (sOB$R)$, homeostasis model assessment index ratio (HOMA-IR).
\end{abstract}




\section{INTRODUCTION}

According to the recommendation of The International Diabetes Federation (IDF), nonalcoholic fatty liver disease (NAFLD) is considered the hepatic manifestation of metabolic syndrome which includes central obesity, hypertriglyceridemia, low high density lipoprotein cholesterol (HDL-C), high blood pressure and high fasting glucose $\mathrm{e}^{(\mathbf{1})}$. NAFLD remains a leading cause of chronic liver disease characterized by macrovescicular hepatic fat accumulation occurring in individuals without relevant alcohol consumption. It has an extensive clinical spectrum ranging from asymptomatic fatty liver (NAFL) to nonalcoholic steatohepatitis (NASH) and cirrhosis (2). Most often, fatty liver has a benign course, but in approximately 20-30\% of the cases, histological signs of fibrosis and necroinflammatory injury that define NASH are present ${ }^{(3)}$.

Although NAFLD can develop in non-obese subjects, it should be suspected when there are metabolic risk factors and/or characteristic changes on hepatic ultrasonography and is diagnosed by ultrasonography, assessment of liver function after exclusion of other liver diseases. Liver biopsy, the keystone of diagnosis of NAFLD, should be considered when there is diagnostic uncertainty, and for patients at risk of advanced fibrosis, however biopsy has its limitations ${ }^{(\mathbf{(}) .}$ Moreover, imaging techniques including ultrasonography, CT scan and MRI cannot differentiate steatohepatitis or fibrosis from simple steatosis $^{(5)}$ and ALT activities may be within the normal range among patients with NAFLD (6) and a significant proportion of patients with normal ALT have bridging fibrosis and even cirrhosis on histology ${ }^{(7)}$. Therefore, the availability of other biochemical markers of NAFL and NASH has tremendous potential to alter management strategies for these conditions, as well as to monitor disease activity ${ }^{(\mathbf{8})}$.

In the last decade, adipose tissue has emerged as an endocrine organ, with a key role in energy homeostasis, since its metabolic products, adipokines, exert local, peripheral, and central effects ${ }^{(9)}$. Both adipokines such as leptin or adiponectin, resistin and fat- or liver-derived cytokines such as tumor necrosis factor $\alpha$ (TNF$\alpha$ ) and interleukin 6 (IL-6) could act as pathogenic factors in NASH ${ }^{(10)}$. In the setting of liver injury, most adipokines are also produced and secreted by hepatocytes ${ }^{(\mathbf{1 1})}$.

Leptin is a cytokine primarily secreted from adipocytes of white fat plays an important role in the regulation of body weight in mammals ${ }^{(\mathbf{1 2})}$. Leptin expression also occurs other sites such as placenta, skeletal muscle, the stomach fundus, and culture-activated hepatic stellate cells (HSCs) ${ }^{(\mathbf{1 3})}$. Attention has been suggested a critical role of leptin in hepatic inflammation and fibrogenesis, however, the precise mechanisms underlying the profibrogenic action of leptin in the liver has not been well elucidated ${ }^{(\mathbf{1 4})}$.

Leptin action in peripheral tissues involves interaction with specific transmembrane receptors. The leptin receptor $(\mathrm{Ob}-\mathrm{R})$, which is a member 
of the class-1 cytokine receptor family, may be an important determinant of leptin sensitivity. Ob-R was originally demonstrated in hypothalamic neurons, through which leptin regulates food intake and body weight $^{(15)}$. Along side several membrane-bound isoforms of $\mathrm{Ob}-\mathrm{R}$, with varying cytoplasmic length and with the same extracellular domain, a soluble form of the leptin receptor (sOb-R) can be demonstrated. sOb-R represents the main leptin-binding compound in plasma, which results in fractions of bound and free leptin in plasma $^{(16)}$. The balance between the free form, the rapidly bioavailable compartment, and bound leptin regulates leptin bioavailability ${ }^{(17)}$.

The relationship between sOB-R and NAFLD is an unresolved issue. Since concentrations of sOB-R are decreased in obese subjects when compared with lean controls .Nevertheless, levels of sOB-R can provide an indication of free leptin ${ }^{(\mathbf{1 8})}$.

A growing body of evidence supports a central role of TNF- $\alpha$ and other inflammatory cytokines in the progression from fatty liver to NASH. A cytokine imbalance may play an important role in the development of NASH ${ }^{(19)}$.

TNF- $\alpha$ is an important cytokine in the development of various liver diseases. TNF- $\alpha$ recruit inflammatory cells and triggers the production of other cytokines, which initiate the healing process leading to fibrogenesis $^{(\mathbf{2 0 )}}$. The proinflammatory cytokines induced by TNF- $\alpha$ are thought to be responsible for the pathogenesis of advanced liver diseases associated with alcohol ${ }^{(21)}$. TNF $\alpha$ has also a central role in the development of fatty liver and subsequently NASH. Elevated circulating TNF $\alpha$ level are associated with obesity and insulin resistance both in animal models and humans (22)

Adiponectin is a $30 \mathrm{kDa}$ protein abundantly and selectively expressed in white adipose tissue. Its role in insulin resistance and atherosclerosis has been well established. Recently, two adiponectin receptors have been cloned in mouse and humans, and both are expressed in liver ${ }^{(23)}$. Although the available evidence indicates that adiponectin stimulates fatty acid oxidation in liver and skeletal muscle, it is still unknown whether circulating adiponectin levels are altered in disorders of hepatic metabolism of energy substrates ${ }^{(24)}$.

The aim of the present study was to evaluate the relationship between leptin, sOB-R, TNF $-\alpha$, adiponectin and IR in the clinical setting of NAFL, and also to clarify their potential role in disease progression.

Patients and Methods: The present study was carried out on 60 individuals. They were 33 females and 27 males, their ages ranged 43-53 years, matched for age, sex, and body mass index (BMI). They were divided into three equal groups:

Group I: Normal healthy volunteers (11 females and 9 males) with normal biochemical and ultrasonic findings comprised the control group with a mean body mass index (BMI) of 25.2 $\pm 2.6 \mathrm{~kg} / \mathrm{m}^{2}$.

Group II: Patients with fatty liver (12 females and 8 males), with a mean BMI of $31.8 \pm 1.1 \mathrm{~kg} / \mathrm{m}^{2}$.

Group III: Patients with steatohepatitis (10 females and 10 
males), with a mean body mass index (BMI) of $32.7 \pm 1.4 \mathrm{~kg} / \mathrm{m}^{2}$.

The diagnosis of fatty liver (group II) was based on the presence of obesity (BMI $>30 \mathrm{~kg} / \mathrm{m}^{2}$ ), bright hepatic echotexture (compared with kidney and/or spleen), deep attenuation and vascular blunting and persistently normal AST and ALT activities, while the diagnosis of steatohepatitis (group III) was based on the presence of obesity, bright liver on ultrasound examination and increased serum AST and ALT enzymes activity for more than 3 months after exclusion of other causes of liver diseases such as alcoholic liver disease, viral hepatitis, druginduced liver disease, primary biliary cirrhosis, biliary obstruction, and metabolic liver diseases ${ }^{\mathbf{( 2 5 , 2 6 )} \text {. }}$

After an overnight fasting, blood samples were taken from every investigated subject under complete aseptic conditions. The obtained sera were stored in aliquots at $-70^{\circ} \mathrm{C}$ till the time of use.

All patients were selected from Inpatient and Outpatient Clinics of Tropical Medicine Department, Faculty of Medicine, Tanta University Hospital,. Written consent was taken from every investigated subject.

All patients and controls were subjected to;

- Thorough history taking and full clinical examination.

- Routine laboratory investigations including:

1. Liver function tests including, serum ALT and AST enzymes activity by automated enzymatic methods.

2. Lipid profile including total cholesterol, triglycerides, high- density lipoprotein-cholesterol (HDL-C) and low-density lipoprotein-cholesterol (LDL-C) measured by automated enzymatic methods.

3. Fasting blood glucose level which was measured by the glucose oxidase method.

4. Hepatitis markers; HBsAg and HCV antibodies by enzyme linked immunosorbent assay (ELISA) technique.

5. Ultrasound scanning: All patients underwent upper abdominal ultrasonography. Bright liver at ultrasound scanning was defined as an evident sonographic contrast between hepatic and renal parenchyma, vessel blurring, focal sparing, and narrowing of the lumen of the hepatic veins, according to international guidelines (27). Control individuals showed no ultrasonic abnormality.

- Specific laboratory investigations including:

1.Serum leptin level was measured using human Leptin ELISA kit supplied by Diagnostic System Laboratories, INC, USA (28).

2. Serum sOB-R levels were measured using an ELISA commercial kit (Alexis Biochemicals, San Diego, CA, USA) ${ }^{\text {(29). }}$

3. Serum Insulin level was measured by ELISA using human commercially available kits ${ }^{(30)}$.

4. Serum TNF-a level was determined by using Quantikine Human TNF- $\alpha$ ELISA kits provided by Roche Diagnostics GmbH, Mannheim, Germany ${ }^{(31) .}$ 


\section{Serum adiponectin \\ concentration was determined \\ using Quntikine Human Adiponectin ELISA kit supplied by R\&D systems Germany ${ }^{(32) .}$}

6. Homeostasis Model Assessment Method (HOMA) as an index of insulin resistance (IR) was calculated on the basis of fasting values of plasma glucose in $\mathrm{mmol} / \mathrm{l}$. and insulin, according to the homeostasis model assessment (HOMA) insulin sensitivity (HOMA) model formula: HOMA IR = fasting insulin $(\mu \mathrm{U} / \mathrm{l}$. $) \times$ fasting glucose $(\mathrm{mmol} / \mathrm{l}.) / 22.5^{(33)}$.

\section{Statistical analysis}

Statistical analysis was performed with SPSS 11.5 program. Results were expressed as mean \pm SD. Comparison between the two groups was made with Student's t-test. Values are significant when $\mathrm{P}<0.05$. Pearson's and Spearman's rank correlations were used to detect the associations between serum levels and various demographic, anthropometric, and biochemical variables.

\section{RESULTS}

Demographic, anthropometric and biochemical characteristics of all groups are illustrated in table 1 and fig 1. There was no significant difference between all groups as regards age and sex $(\mathrm{P}>0.05)$. Body mass index was significantly higher in group II and group III as compared to the control group (P1 \& P2 $<0.05)$, with non significant difference between them $(\mathrm{P} 3>0.05)$. Serum triglycerides were significantly higher in both obese subjects as compared to control group $\left(\mathrm{P}_{1}<0.05, \mathrm{P} 2<0.05\right.$ respectively $)$ whereas total cholesterol, LDL- C and HDL-C showed non significant difference in all groups $\left(\mathrm{P}_{1}>0.05, \mathrm{P}_{2}\right.$ $>0.05$ and $\mathrm{P}_{3}>0.05$ respectively).

There was a significant increase in ALT and AST enzymes activity in group III as compared to control and group II $\left(\mathrm{P}_{2}<0.05, \quad \mathrm{P}_{3}<0.05\right.$ respectively). The fasting blood glucose levels showed no significant differences between all groups $\left(\mathrm{P}_{1}>0.05, \quad \mathrm{P}_{2}>0.05\right.$ and $\mathrm{P}_{3}>0.05$ respectively), insulin levels and HOMA-IR were significantly higher in groups II and III compared with the control group $\left(\mathrm{P}_{1}<0.05, \mathrm{P}_{2}<0.05\right.$ respectively), with no significant difference between them $\left(\mathrm{P}_{3}>0.05\right)$.

Serum leptin levels showed a significant increase in groups II and III compared to the control group $\left(\mathrm{P}_{1}<0.05\right.$ and $\mathrm{P}_{2}<0.001$ respectively), with significantly higher levels in group III than group II $\left(\mathrm{P}_{3}<0.05\right)$. In contrast, serum sOB-R levels were significantly lower in both groups II and III compared to the control group $\left(\mathrm{P}_{1}<0.05\right.$ and $\mathrm{P}_{2}<0.05$ respectively), with still significantly lower levels in patients of group III $\left(\mathrm{P}_{3}<0.05\right)$. Serum TNF- $\alpha$ levels showed a significant increase in both patients' groups as compared to the control group $\left(\mathrm{P}_{1}<0.05\right.$ and $\mathrm{P}_{2}<0.001$ respectively), with significantly higher levels in patients with group III $\left(\mathrm{P}_{3}<0.05\right)$. On the other hand, serum adiponectin levels showed a significant decrease in patients with group III when compared to group I $\left(\mathrm{P}_{2}<0.001\right)$ and group II $\left(\mathrm{P}_{3}<0.05\right.$, while the difference was non significant between the groups I and 
II, ( $\left.\mathrm{P}_{1}>0.05\right)$, (table 2 and fig 2 ). Serum leptin levels were significantly increased and sOB-R levels were significantly decreased in females compared to males in groups II and III $\left(\mathrm{P}_{2}<0.05\right.$ and $\mathrm{P}_{3}<0.05$ respectively) (table 3)

Correlation studies in patients of group II: Tables $(4,5)$ : Serum leptin levels were positively correlated with BMI $\quad(r \quad=0.863 \& \quad \mathrm{P}<0.001) \quad$ and HOMA-IR ( $r=0.536 \&$ \& $<0.001)$. sOB-R levels were negatively correlated with serum leptin levels $(\mathrm{r}=-0.485 \& \mathrm{P}<0.05)$, BMI $(\mathrm{r}=-0.425 \&$ $\mathrm{P}<0.05)$, HOMA-IR $(\mathrm{r}=-0.362 \&$ $\mathrm{P}<0.05)$.

Serum TNF- $\alpha$ was positively correlated with serum leptin levels $(\mathrm{r}=0.440$ \& $\mathrm{P}<0.05)$, BMI $(\mathrm{r}=0.547 \&$ $\mathrm{P}<0.05)$ and HOMA-IR $(\mathrm{r}=0.471 \&$ $\mathrm{P}<0.05$ ), while it was negatively correlated with sOB-R levels $(\mathrm{r}=$ $0.423 \& \mathrm{P}<0.05)$.

On the contrary, serum adiponectin levels were negatively correlated with BMI $(r=-0.525 \&$ $\mathrm{P}<0.05)$ and HOMA-IR $(\mathrm{r}=-0.536 \&$ $\mathrm{P}<0.05)$, in addition to serum leptin level $(\mathrm{r}=-0.428 \& \mathrm{P}<0.05)$ and TNF$\alpha(r=-0.475 \& \mathrm{P}<0.05)$.
Correlation studies in patients of group III: Tables 6, 7. Serum leptin level was positively correlated with BMI $(r=0.569 \& \mathrm{P}<0.001)$, HOMAIR $(r=0.458 \& \mathrm{P}<0.05)$, serum ALT $(\mathrm{r}=0.658 \& \mathrm{P}<0.001)$, and serum AST activities $(r=0.475 \& \mathrm{P}<0.05)$. sOB-R levels were negatively correlated with serum leptin level $(\mathrm{r}=$ $-0.517 \& \quad \mathrm{P}<0.05), \mathrm{BMI},(\mathrm{r}=-0.417 \&$ $\mathrm{P}<0.05)$, HOMA-IR $(\mathrm{r}=-0.538 \& \mathrm{P}$ $<0.001$ ), serum ALT activities ( $\mathrm{r}=$ $0.489 \& \mathrm{P}<0.05)$, serum AST levels $(\mathrm{r}=-0.628 \& \mathrm{P}<0.001)$ and.

Serum TNF- $\alpha$ was positively correlated with serum leptin levels $(\mathrm{r}=0.584 \& \mathrm{P}<0.05), \mathrm{BMI},(\mathrm{r}=0.410 \&$ $\mathrm{P}<0.05), \quad$ HOMA-IR $\quad(\mathrm{r}=0.603 \quad \&$ $\mathrm{P}<0.05)$, serum ALT activities $(\mathrm{r}=$ $0.468 \& \mathrm{P}<0.05)$, and serum AST activities $(\mathrm{r}=0.385 \& \mathrm{P}<0.05)$, but was negatively correlated with sOB-R levels $(\mathrm{r}=-0.520 \& \mathrm{P}<0.05)$.

On the contrary, serum adiponectin levels were negatively correlated with serum leptin levels $(\mathrm{r}=-0.562 \& \mathrm{P}<0.001)$, TNF- $\alpha \quad(\mathrm{r}=-$ $0.532 \& \mathrm{P}<0.05)$, in addition to $\mathrm{BMI}$ $(\mathrm{r}=-0.428 \& \mathrm{P}<0.05)$, HOMA-IR $(\mathrm{r}=-$ $0.524 \& \mathrm{P}<0.001)$, serum ALT $(\mathrm{r}=$ $0.447 \& \mathrm{P}<0.05)$ and AST activities $(\mathrm{r}=-0.488$ \& $\mathrm{P}<0.05)$. 
Table 1: Demographic, anthropometric and biochemical characteristics of the studied groups.

\begin{tabular}{|l|l|l|l|l|l|l|}
\hline & $\begin{array}{l}\text { Group I } \\
\text { (Control) } \\
(\mathbf{n}=\mathbf{2 0})\end{array}$ & $\begin{array}{l}\text { Group II } \\
\text { (NAFLD } \\
\text { (n= 20) }\end{array}$ & $\begin{array}{l}\text { Group III } \\
\text { (NASH) } \\
\text { (n= 20) }\end{array}$ & $\mathbf{P}_{\mathbf{1}}$ & $\mathbf{P}_{\mathbf{2}}$ & $\mathbf{P}_{\mathbf{3}}$ \\
\hline Age (years) & $40 \pm 12$ & $39 \pm 12$ & $42 \pm 13$ & $>0.05$ & $>0.05$ & $>0.05$ \\
\hline Sex (F/M) & $11 / 9$ & $12 / 8$ & $10 / 10$ & $>0.05$ & $>0.05$ & $>0.05$ \\
\hline BMI $\left(\mathrm{kg} / \mathrm{m}^{2}\right)$ & $25.2 \pm 2.6$ & $28.9 \pm 5.8$ & $32.7 \pm 1.4$ & $<0.05^{*}$ & $<0.05^{*}$ & $>0.05$ \\
\hline Total & $153 \pm 33.5$ & $164 \pm 40.1$ & $167 \pm 37.2$ & $>0.05$ & $>0.05$ & $>0.05$ \\
\hline HDL-C (mg/dl) & $52 \pm 11$ & $50 \pm 10$ & $47 \pm 8$ & $>0.05$ & $>0.05$ & $>0.05$ \\
\hline LDL-C $(\mathrm{mg} / \mathrm{dl})$ & $95 \pm 30$ & $94 \pm 33$ & $97 \pm 26$ & $>0.05$ & $>0.05$ & $>0.05$ \\
\hline Triglycerides $(\mathrm{mg} / \mathrm{dl})$ & $102.5 \pm 20.16$ & $129.5 \pm 20.60$ & $150.56 \pm 30.7$ & $<0.05^{*}$ & $<0.01^{* *}$ & $<0.05^{*}$ \\
\hline AST(U/l) & $22.00 \pm 14.79$ & $30.1 \pm 7.00$ & $70.72 \pm 68.04$ & $>0.05$ & $<0.001^{* *}$ & $<0.001^{* *}$ \\
\hline ALT $(\mathrm{U} / \mathrm{l})$ & $20.60 \pm 9.97$ & $25.30 \pm 5.1$ & $62.00 \pm 30$ & $>0.05$ & $<0.001^{* *}$ & $<0.001^{* *}$ \\
\hline Fasting glucose & $5.33 \pm 0.26$ & $5.99 \pm 0.50$ & $5.95 \pm 0.42$ & $>0.05$ & $>0.05$ & $>0.05$ \\
\hline Fasting insulin $(\mu \mathrm{U} / \mathrm{l})$ & $8.7 \pm 0.6$ & $13.9 \pm 2.0$ & $14.4 \pm 2.5$ & $<0.05^{*}$ & $<0.001^{* *}$ & $>0.05$ \\
\hline HOMA-IR & $1.95 \pm 0.26$ & $3.30 \pm 0.40$ & $3.61 \pm 0.55$ & $<0.05^{*}$ & $<0.05^{*}$ & $>0.05$ \\
\hline
\end{tabular}

Table 2: Mean serum levels of leptin, sOB-R, TNF $\alpha$ and adiponectin in all studied groups.

\begin{tabular}{|l|l|l|l|l|l|l|}
\hline & $\begin{array}{l}\text { Group I } \\
\text { Control) } \\
(\mathbf{n = 2 0 )}\end{array}$ & $\begin{array}{l}\text { Group II } \\
\text { (NAFLD) } \\
(\mathbf{n = 2 0 )}\end{array}$ & $\begin{array}{l}\text { Group III } \\
\text { (NASH) } \\
(\mathbf{n = 2 0})\end{array}$ & $\mathbf{P}_{\mathbf{1}}$ & $\mathbf{P}_{\mathbf{2}}$ & $\mathbf{P}_{\mathbf{3}}$ \\
\hline Serum leptin, (ng/ml) & $12.7 \pm 5.3$ & $17.8 \pm 8.5$ & $24.2 \pm 6.8$ & $<0.05^{*}$ & $<0.001^{* *}$ & $<0.05^{*}$ \\
\hline Serum sOB-R, (ng /ml) & $5.4 \pm 1.8$ & $4.2 \pm 0.5$ & $2.5 \pm 0.6$ & $<0.05^{*}$ & $<0.05^{*}$ & $>0.05^{*}$ \\
\hline Serum TNF- $\boldsymbol{\alpha},(\mathbf{p g} / \mathbf{m l})$ & $2.3 \pm 1.7$ & $5.78 \pm 17.2$ & $9.2 \pm 20.3$ & $<0.05^{*}$ & $<0.001^{* *}$ & $<0.05^{*}$ \\
\hline $\begin{array}{l}\text { Serum Adiponectin } \\
(\boldsymbol{\mu g} / \mathbf{m l})\end{array}$ & $15.5 \pm 1.0$ & $14.7 \pm 2.1$ & $7.3 \pm 0.8$ & $>0.05$ & $<0.001^{* *}$ & $<0.05^{*}$ \\
\hline
\end{tabular}

$P_{1}:$ GII vs GI $\quad P_{2}:$ GIII vs GI $\quad P_{3}$ :GIII vs GII

Table 3: Statistical comparison between serum leptin and its soluble receptor ( sOB-

$\mathrm{R})$ levels in relation to sex.

\begin{tabular}{|c|c|c|c|c|c|c|c|c|c|}
\hline & \multicolumn{3}{|c|}{ Female } & \multicolumn{6}{|l|}{ Male } \\
\hline & G I & G II & G III & G I & G II & G III & & & \\
\hline Number of subjects & 11 & 12 & 10 & 9 & 8 & 10 & $\mathbf{P}_{1}$ & $\mathbf{P}_{\mathbf{2}}$ & $\mathbf{P}_{3}$ \\
\hline $\begin{array}{l}\text { Serum leptin (ng } \\
/ / \mathrm{ml})\end{array}$ & $\begin{array}{l}12.1 \\
\pm 5.3\end{array}$ & $\begin{array}{l}17.8 \\
\pm 8.5\end{array}$ & $\begin{array}{l}24.20 \\
\pm 6.80\end{array}$ & $\begin{array}{l}11.43 \\
+4.32\end{array}$ & $\begin{array}{l}15.63 \\
\pm 8.34\end{array}$ & $\begin{array}{l}21.53 \\
\pm 6.9\end{array}$ & $>0.05$ & $<0.05^{*}$ & $<0.05^{*}$ \\
\hline $\begin{array}{l}\text { Serum sOB-R } \\
(\mathrm{ng} / \mathrm{ml})\end{array}$ & $\begin{array}{l}5.40 \\
\pm 1.2\end{array}$ & $\begin{array}{l}4.20 \\
\pm 5.9\end{array}$ & $\begin{array}{l}3.50 \\
\pm 2\end{array}$ & $\begin{array}{l}6.91 \\
\pm 1.90\end{array}$ & $\begin{array}{l}5.67 \\
\pm 0.60\end{array}$ & $\begin{array}{l}4.90 \\
\pm 0.80\end{array}$ & $>0.05$ & $<0.05^{*}$ & $<0.05^{*}$ \\
\hline
\end{tabular}

$\mathrm{P}_{1}$ comparison between (GI female) \& (GI male)

$\mathrm{P}_{2}$ comparison between (GII female) \& (GII male)

$\mathrm{P}_{3}$ comparison between (GIII female) \& (GIII male) 
Table 4: Correlation matrix between the studied parameters and BMI, HOMA-IR and liver enzymes in group II (NAFLD).

\begin{tabular}{|c|c|c|c|c|c|}
\hline & BMI & HOMA-IR & ALT & AST \\
\hline \multirow{2}{*}{$\begin{array}{l}\text { Serum leptin } \\
(\mathrm{ng} / \mathrm{ml})\end{array}$} & $\mathbf{r}$ & 0.863 & 0.536 & 0.325 & 0.241 \\
\hline & P-value & $<0.001^{*}$ & $<0.001 *$ & $>0.05$ & $>0.05$ \\
\hline \multirow{2}{*}{$\begin{array}{l}\text { Serum sOB-R } \\
(\mathrm{ng} / \mathrm{ml})\end{array}$} & $\mathbf{r}$ & -0.425 & -0.362 & 0.102 & 0.253 \\
\hline & P-value & $<0.05^{*}$ & $<0.05^{*}$ & $>0.05$ & $>0.05$ \\
\hline \multirow{2}{*}{$\begin{array}{l}\text { Serum TNF } \alpha \\
(\mathrm{pg} / \mathrm{ml})\end{array}$} & $\mathbf{r}$ & 0.547 & 0.471 & 0.221 & 0.258 \\
\hline & P-value & $<0.05^{*}$ & $<0.05^{*}$ & $>0.05$ & $>0.05$ \\
\hline \multirow{2}{*}{$\begin{array}{l}\text { Serum adiponectin } \\
(\mu \mathrm{g} / \mathrm{ml})\end{array}$} & $\mathbf{r}$ & -0.525 & -0.536 & 0.369 & 0.247 \\
\hline & P-value & $<0.05^{*}$ & $<0.05^{*}$ & $>0.05$ & $>0.05$ \\
\hline
\end{tabular}

Table (5): Correlation matrix between all studied parameters in group II (NAFLD).

\begin{tabular}{|l|l|l|}
\hline & r. value & p. value \\
\hline Leptin $(\mathbf{n g} / \mathbf{m l}) \&$ TNF $\boldsymbol{\alpha}(\mathbf{p g} / \mathbf{m l})$ & 0.440 & $<0.05^{*}$ \\
\hline Leptin $(\mathbf{n g} / \mathbf{m l}) \&$ adiponectin $(\boldsymbol{\mu g} / \mathbf{m l})$ & -0.428 & $<0.05^{*}$ \\
\hline Leptin $(\mathbf{n g} / \mathbf{m l}) \&$ sOB-R $(\mathbf{n g} / \mathbf{m l})$ & -0.485 & $<0.05^{*}$ \\
\hline sOB-R $(\mathbf{n g} / \mathbf{m l}) \&$ TNF $\boldsymbol{\alpha}(\mathbf{p g} / \mathbf{m l})$ & -0.423 & $<0.05^{*}$ \\
\hline Adiponectin $(\boldsymbol{\mu g} / \mathbf{m l}) \& \mathbf{~ S O B - R}(\mathbf{n g} / \mathbf{m l})$ & 0.488 & $<0.05^{*}$ \\
\hline Adiponectin $(\boldsymbol{\mu g} / \mathbf{m l}) \&$ TNF $\boldsymbol{\alpha}(\mathbf{p g} / \mathbf{m l})$ & -0.475 & $<0.05^{*}$ \\
\hline
\end{tabular}

Table 6: Correlation matrix between the studied parameters and BMI, HOMA and liver enzymes in group III (NASH)

\begin{tabular}{|l|l|l|l|l|l|}
\hline \multicolumn{2}{|c|}{} & BMI & HOMA-IR & ALT & AST \\
\hline \multirow{2}{*}{$\begin{array}{l}\text { Serum leptin } \\
(\text { ng } / m l)\end{array}$} & R & 0.569 & 0.458 & 0.658 & 0.475 \\
\hline \multirow{2}{*}{$\begin{array}{l}\text { Serum sOB-R } \\
\text { (ng /ml) }\end{array}$} & P-value & $<0.001^{* *}$ & $<0.05^{*}$ & $<0.001^{* *}$ & $<0.05^{*}$ \\
\hline \multirow{2}{*}{$\begin{array}{l}\text { Serum TNF } \boldsymbol{\alpha} \\
(\mathbf{p g} / \mathbf{m l})\end{array}$} & $\mathbf{R}$ & -0.417 & -0.538 & -0.489 & -0.628 \\
\hline \multirow{2}{*}{$\begin{array}{l}\text { Serum adiponectin } \\
(\boldsymbol{\mu g} / \mathbf{m l})\end{array}$} & $\mathbf{R}$ & $<0.05^{*}$ & $<0.001^{* *}$ & $<0.05^{*}$ & $<0.001^{* *}$ \\
\cline { 2 - 6 } & P-value & 0.410 & 0.603 & 0.468 & 0.385 \\
\cline { 2 - 6 } & R & $-0.05^{*}$ & $<0.05^{*}$ & $<0.05^{*}$ & $<0.05^{*}$ \\
\hline
\end{tabular}

Table (7): Correlation matrix between all studied parameters in group III (NASH).

\begin{tabular}{|l|l|l|}
\hline & r. value & p. value \\
\hline Leptin (ng /ml) \& TNF $\boldsymbol{\alpha}(\mathbf{p g} / \mathbf{m l})$ & 0.584 & $<0.05^{*}$ \\
\hline Leptin $(\mathbf{n g} / \mathbf{m l}) \&$ adiponectin $(\boldsymbol{\mu g} / \mathbf{m l})$ & -0.562 & $<0.05^{*}$ \\
\hline Leptin (ng /ml) \& sOB-R (ng /ml) & -0.517 & $<0.05^{*}$ \\
\hline sOB-R (ng /ml) \& TNF $\boldsymbol{\alpha}(\mathbf{p g} / \mathbf{m l})$ & -0.520 & $<0.05^{*}$ \\
\hline Adiponectin $(\boldsymbol{\mu g} / \mathbf{m l}) \& \mathbf{~ s O B - R ~ ( n g ~ / m l ) ~}$ & 0.480 & $<0.05^{*}$ \\
\hline Adiponectin $(\boldsymbol{\mu g} / \mathbf{m l}) \& \mathbf{T N F} \boldsymbol{\alpha}(\mathbf{p g} / \mathbf{m l})$ & -0.532 & $<0.05^{*}$ \\
\hline
\end{tabular}




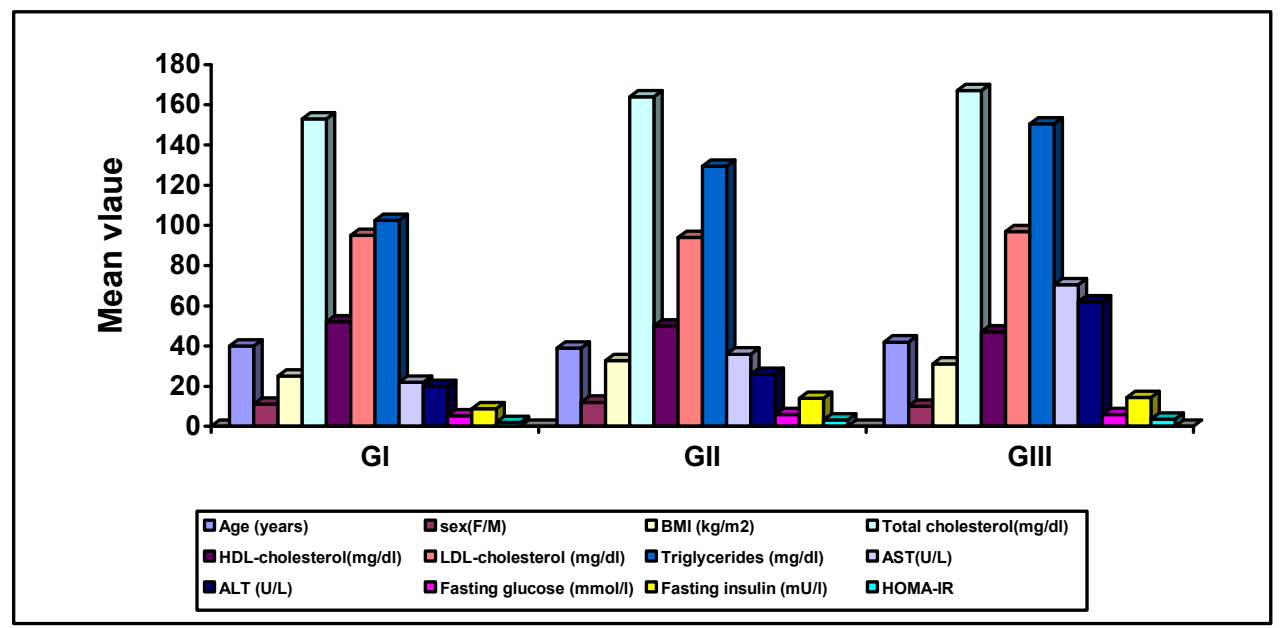

Fig 1: Demographic, anthropometric and biochemical characteristics of the studied groups.

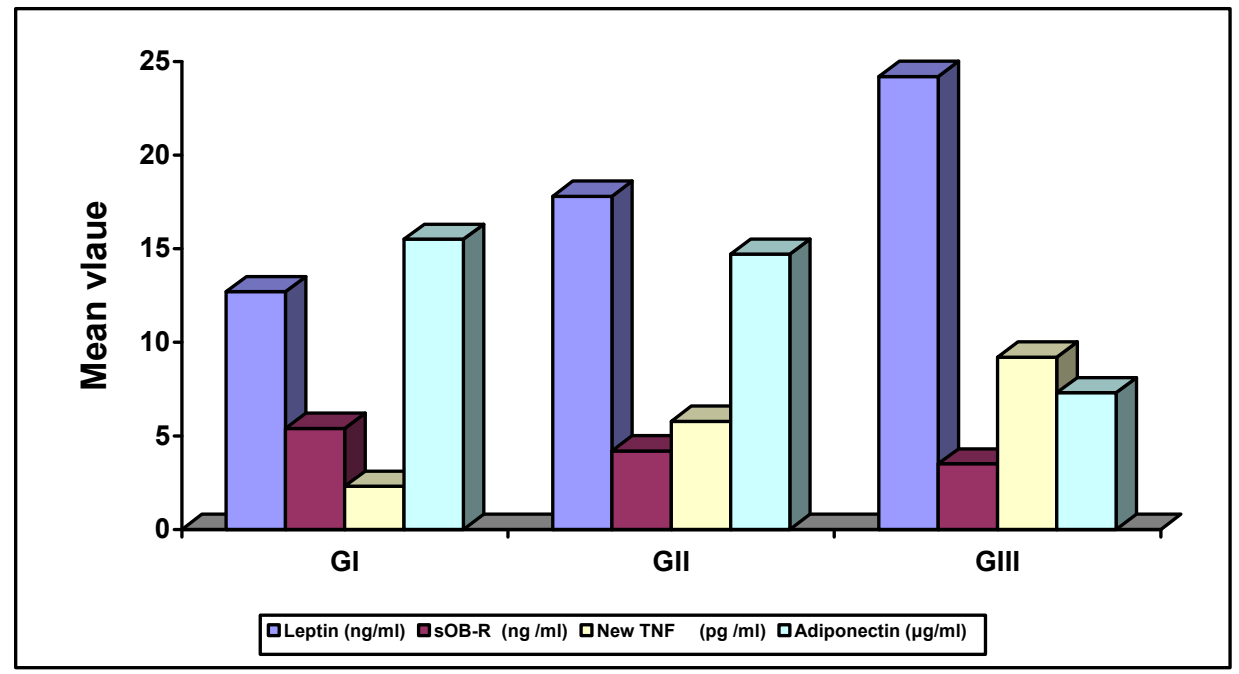

Fig 2: Mean serum levels of leptin, sOB-R, TNF $\alpha$ and adiponectin in all studied groups. 


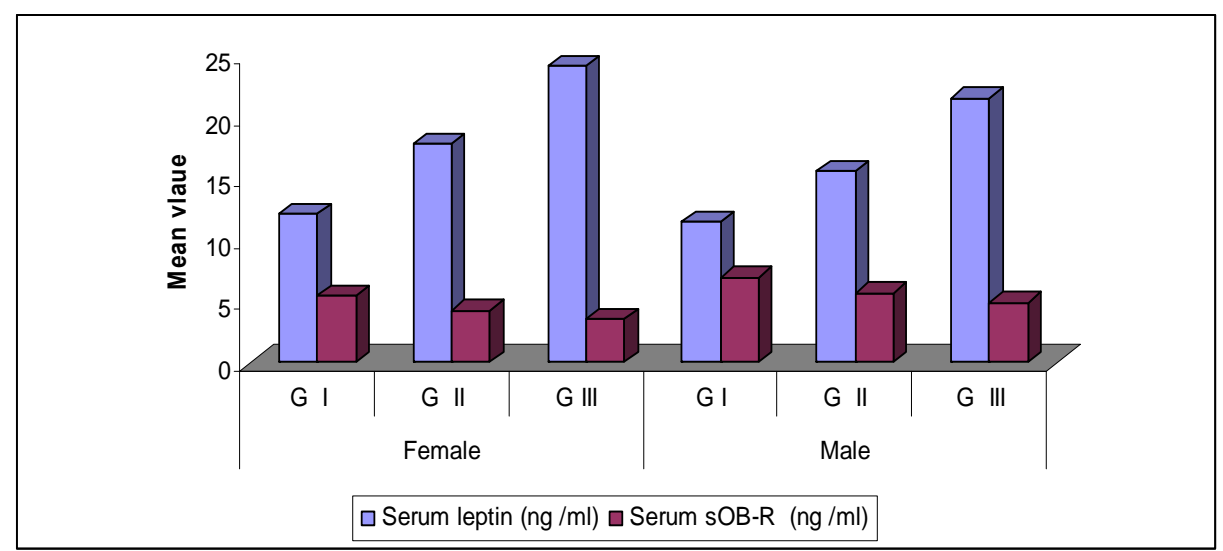

Fig. (3): Statistical comparison between serum leptin and sOB-R levels in relation to sex

\section{DISCUSSION}

Nonalcoholic fatty liver disease (NAFLD) is the hepatic manifestation of the metabolic syndrome and can vary from benign steatosis to endstage liver disease ${ }^{(34)}$. The number of patients with NAFL who have NASH is unclear. That determination is important because inflammation and/or fibrosis dictate the long-term prognosis of that disease ${ }^{(35)}$. Although liver biopsy remains the gold standard for an accurate diagnosis of NASH, as well as for differentiating that condition from simple steatosis, it is unfortunately a costly and an invasive diagnostic procedure ${ }^{(8)}$.Therefore, there is a need for other markers to aid clinical assessment and to enhance the ability to identify patients at risk of developing NASH and liver fibrosis ${ }^{(36)}$. Biomarker use is one such a tool to better identify subjects with NASH in the context of NAFLD, and hopefully to prognosticate patients with that condition $^{(8)}$. There is mounting evidence that cytokines are implicated in the pathogenesis and progression of NAFLD ${ }^{(37)}$. Therefore, the present work aimed to study the relationship between serum leptin, sOB-R, TNF- $\alpha$, adiponectin levels and insulin resistance (IR) in the clinical setting of NAFLD to clarify their potential role in disease progression.

Although insulin resistance (IR) has been identified as a crucial pathophysiologic factor in NAFLD ${ }^{(38)}$, the mechanistic basis of NAFL and NASH remains incompletely understood $^{(39)}$. Also, although complex interactions between genetic determinants, nutritional factors and lifestyle influence IR, it is increasingly recognized that soluble mediators, synthesized both from cells of the immune system and by the adipose tissue, are critically involved in disease manifestation and progression and even more importantly in regulation of insulin 
action. Insulin acts in all cells through binding to its specific receptor and thereby activating a cascade of intracellular signaling events ${ }^{(40)}$. After binding, insulin receptor phosphorylate itself and several members of the insulin-receptor substrate (IRS) family. IRS-1 and IRS-2 are the main mediators of insulin signaling in the liver, controlling insulin sensitivity. The primary mechanism of IR induced by inflammatory mediators is exerted by interference at that level of signaling. ${ }^{(40)}$. In the present study, significantly increased levels of insulin and HOMA-IR were found in both patients' groups compared to the control, with significantly increased serum ALT and AST activities in group III compared to group II, which confirm the frequent association of NAFLD with obesity. These findings are in agreement with those of Rocha et al. (2005) and Fabbrini et al. (2009) who reported obesity in $40 \%$ $100 \%$ of fatty liver and a high BMI, as a frequent association with histological findings of steatohepatitis and fibrosis in patients with NAFLD $^{(41,42)}$.

Similarly, serum leptin levels were significantly increased in the patients' groups compared to the control group, with significantly higher levels in group III than group II, which is consistent with a number of previous studies ${ }^{(\mathbf{4 3}, 44)}$. In addition, serum leptin levels were positively correlated with AST and ALT activities in group III, which is in agreement with the finding of Krawczyk et al. (2009), who reported that the changes of adipohormones levels may be markers of NASH and serum leptin level can be associated with more advanced form of NASH ${ }^{(44)}$. It has been suggested that leptin might cause hepatic steatosis to turn into steatohepatitis by amplifying selected proinflammatory cytokines as TNF- $\alpha$, which may play a significant role in the pathogenesis of NASH as a "second hit" following the development of simple steatosis ${ }^{(\mathbf{4 5})}$. Moreover, a fibrogenic effect of leptin is also accomplished through HSCs, in which leptin is a potent mitogen and apoptosis inhibitor. Activated HSCs acquire the ability to secrete leptin and further promote liver fibrosis ${ }^{(46)}$.

Serum leptin level was positively correlated with BMI and HOMA-IR in groups II \& III, which is consistent with previous studies ${ }^{(\mathbf{4 4}, \mathbf{4 7}}$. It has been also reported that leptin inhibits insulin-stimulated phosphorylation of several intracellular signaling proteins and down-regulates gluconeogenesis, suggesting that leptin may help to induce insulin resistance; an almostuniversal finding in patients with

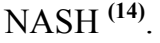

Significantly higher levels of serum leptin were also detected in females than males in both patients' groups, which had also been reported

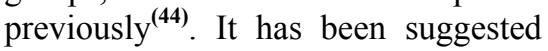
that leptin is exclusively expressed in adipose tissue and secreted from white adipose cells consequently the difference is at least in part, due to the higher percentage body fat in women $^{(16)}$.

In the current study, both patients with NAFL and NASH showed significantly decreased levels of sOB$\mathrm{R}$ levels compared with the control group; with more significantly lower 
levels in the NASH group. Moreover, a negative correlation was also found between serum leptin and its sOB-R levels. It has been suggested that patients who develop NAFLD differ from obese individuals who do not develop NAFLD by having a state of peripheral (hepatic) leptin resistance (inadequate leptin signaling or/and decreased levels of sOB-R ${ }^{(\mathbf{4 8})}$. It has also been suggested that decreased serum levels of sOB-R result inadequate leptin signaling in NAFLD leading to increased serum leptin levels ${ }^{(49)}$. The finding of decreased serum levels of sOB-R in NAFLD suggests an increased resistance of peripheral tissues to the action of leptin, due to decreased expression and secretion of the OB-R ${ }^{(43) .}$

The current study showed also significantly elevated TNF- $\alpha$ levels, associated with obesity and insulin resistance in both NAFL and NASH groups, with significantly higher levels in the latter group. These data are concordant with the results of other studies ${ }^{(\mathbf{5 0 , 5 1 )}}$. It has been shown that TNF- $\alpha$ is highly expressed in the metabolic syndrome, (50) and is considered to have a central role in the development of fatty liver and subsequently NASH. It has a key role in mediating liver injury, given its ability to induce inflammation and apoptosis in hepatocytes under conditions of oxidative stress ${ }^{(52)}$.

Considerable evidence already exists demonstrating that endotoxin can induce steatohepatitis, mediated chiefly via the cytokine, TNF- $\alpha$. In addition, endotoxin- induced stimulation of Kupffer cells has been proposed to be an important initiating event leading to the production of proinflammatory cytokines and oxygen free radicals ${ }^{(52)}$. It has been shown that patients with NASH had an increased expression of TNF-a mRNA both in their liver and adipose tissue compared to obese controls, and this over-expression correlated with histological severity (50). Therefore, there is a strong rationale for measuring the levels of TNF- $\alpha$ in NAFLD.

Adiponectin is one of the beneficial cytokines. It is an important adipokine specifically secreted by adipocytes that circulates at relatively high levels in the blood stream ${ }^{(53)}$. Main functions of that molecule comprise of the down-regulation of inflammatory processes, promotion of lipolysis, and prevention of lipid accumulation. It improves hepatic and peripheral insulin sensitivity ${ }^{(53)}$. It has been proposed that an accumulation of visceral fat might produce inhibiting factors for adiponectin synthesis or secretion $^{(\mathbf{5 4})}$. In the liver, adiponectin prevents steatosis by stimulating mitochondrial $\beta$-oxidation via activation of AMPK (AMP-activated protein kinase) and PPAR- $\alpha$ (peroxisome-proliferator-activated receptor- $\alpha$ ) and down-regulation of SREBP-1c (sterol-regulatory-elementbinding protein-1c), a master regulator of fatty acid synthesis ${ }^{(55)}$. Moreover, adiponectin attenuates oxidative stress, pro-inflammatory cytokine production and ameliorates liver fibrosis via suppression of activated hepatic stellate cell function. It was found that adiponectin prevents hepatic injury by inhibiting the synthesis and/or release of TNF- $\alpha{ }^{(56)}$

In the present study, serum adiponectin levels showed 
significantly decreased levels in both patients' groups compared to control group, and were negatively correlated with BMI and IR. It has been suggested that the low circulating levels of adiponectin is associated with the development of NASH in patients with steatosis and progression of NASH towards cirrhosis ${ }^{(53,54)}$. Moreover, some authors have demonstrated that lower adiponectin levels were associated with more extensive necroinflammation in the setting of NAFLD and recommended decreased adiponectin level as a reliable laboratory marker of NASH $(\mathbf{5 7}, \mathbf{5 8})$.

The highly significant decreased serum adiponectin levels in patients with NAFL compared with the control group, found in our study and others, keep with a proposed protective effect of that cytokine and suggest elevation of adiponectin as a desirable therapeutic target in NAFLD, given the fact of normal serum AST and ALT activities in these cases.

\section{CONCLUSION}

These data strongly suggest a role of leptin, sOB-R, TNF- $\alpha$, and adiponectin in the pathogenesis of NAFLD in obese individuals and further confirm the association between these adipokine changes and liver disease in patients with NASH. Measurement of serum TNF- $\alpha$, serum leptin and/or adiponectin may be helpful biochemical markers of NAFLD, particularly when serum AST and ALT are within normal limits.

\section{REFERENCES}

1. Alberti KG., Zimmet P. and Shaw J. IDF (2005): Epidemiology Task Force Consensus Group. The metabolic syndrome - a new worldwide definition. Lancet 366: 10591062.

2. Marchesini G., Bugianesi E., Forlani G., Cerrelli F., Lenzi M., Manini R., Natale S., Vanni E., Villanova N., Melchionda N., Rizzetto M. (2003): Nonalcoholic fatty liver, steatohepatitis, and the metabolic syndrome. Hepatology 37:917923.

3. Farrell G.C., and Larter C. Z. (2006): Nonalcoholic fatty liver disease: from steatosis to cirrhosis, Hepatology 43, (2 suppl., 1): S99-S112.

4. Cheung O., Sanyal A.J. (2010): Recent advances in nonalcoholic fatty liver disease. Curr. Opin. Gastroenterol., 26(3):202-8.

5. Saadeh S, Younossi ZM, Remer EM, Gramlich T, Ong JP, Hurley M, Mullen KD, Cooper JN, Sheridan MJ.( 2002): The utility of radiological imaging in nonalcoholic fatty liver disease. Gastroenterology 123(3):745-50.

6. Mofrad P., Contos M.J., Haque M., Sargeant C., Fisher R.A., Luketic V.A., Sterling R.K., Shiffman M.L., Stravitz R.T., Sanyal A.J. (2003): Clinical and histologic spectrum of nonalcoholic fatty liver disease associated with normal ALT values. Hepatology 37(6):128692. 
7. Angulo P., Keach J.C., Batts K.P., Lindor K.D. (1999): Independent predictors of liver fibrosis in patients with nonalcoholic steatohepatitis. Hepatology.30(6):1356-62.

8. Wieckowska A., Feldstein A.E. (2008): Diagnosis of nonalcoholic fatty liver disease: invasive versus noninvasive. Semin. Liver Dis., 28: 386-395.

9. Greenberg A. S., and Obin M. S. (2006): "Obesity and the role of adipose tissue in inflammation and metabolism," Am. J. Clin. Nutr., 83:461S-465S.

10. Lemoine M., Ratziu V., Kim M., Maachi M., Wendum D., Paye F., Bastard J.P., Poupon R., Housset C., Capeau J., Serfaty L. (2009): Serum adipokine levels predictive of liver injury in non-alcoholic fatty liver disease.Liver Int., 29(9):1431-8.

11. Serfaty L. (2009): Serum Adipokine Levels Predictive of Liver Injury in Non-alcoholic Fatty Liver Disease. Liver International $29: 1431-1438$.

12. Friedman J.M., and Halas J.L. (1998): Leptin and the regulation of body weight in mammals. Nature 395(6704):763-770.

13. Zhao Y., Sun R., You L., Gao C., Tian Z. (2003): Expression of leptin receptors and response to leptin stimulation of human natural killer cell lines. Biochem. Biophys. Res. Commun., 300: 247-252.

14. Bethanis S.K., Theocharis S.E. (2006): Leptin in the field of hepatic fibrosis: a pivotal or an incidental player? Dig. Dis . Sci., 51(10):1685-96.

15. Tartaglia L.A., Dembski M., Weng X., Deng N., et al.,(1995): Identification and expression cloning of a leptin receptor, OBR. Cell 83: 1263-1271.

16. Lammert A., Kiess W., Bottner A., Glasow A., Kratzsch J. (2001): Soluble leptin receptor represents the main leptin binding activity in human blood. Biochem. Biophys. Res. Commun., 283: 982-988.

17. Lahlou N., Clement K., Carel J.C., Vaisse C., Lotton C., Le Bihan Y., Basdevant A., Lebouc Y., Froguel P., Roger M., GuyGrand B. (2000): Soluble leptin receptor in serum of subjects with complete resistance to leptin: relation to fat mass. Diabetes 49: 1347-1352.

18. Van Dielen F.M., van t., Veer C., Buurman W.A., Greve J.W. (2002): Leptin and soluble leptin receptor levels in obese and weight losing individuals. J. Clin. Endocrinol. Metab., 87: 17081716.

19. Tilg H., Diehl A.M. (2000): Cytokines in alcoholic and nonalcoholic steatohepatitis. N. Engl. J. Med., 343: 1467-76.

20. Youssef W., Mc Cullough A.J. (2002): Diabetes mellitus, obesity, and hepatic steatosis. Semin. Gastrointest. Dis., 13: 1730 .

21. Nagata K., Suzuki H., Sakaguchi S. (2007): Common pathogenic mechanism in development progression of liver injury caused by non-alcoholic or alcoholic steatohepatitis. J 
.Toxicol. Sci., 32 (5):453-68. Review.

22. Medina J., Fernández-Salazar L.I., García-Buey L, MorenoOtero R. (2004): Approach to the pathogenesis and treatment of nonalcoholic steatohepatitis. Diabetes Care 27(8):2057-66. Review.

23. Yamauchi T., Kamon J., Ito Y., Tsuchida A., et al., (2003): Cloning of adiponectin receptors that mediate antidiabetic metabolic effects. Nature 423 762-769.

24. Xu A., Wang Y., Keshaw H., Xu L.Y., Lam K.S., \& Cooper G.J. (2003): The fat-derived hormone adiponectin alleviates alcoholic and non alcoholic fatty liver diseases in mice. J. Clin. Invest., 112 91-100.

25. Chitturi S., Farrell G.C., Hashimoto E., et al. (2007): Non-alcoholic fatty liver disease in the Asia-Pacific region: Definitions and overview of proposed guidelines. J. Gastroenterol. Hepatol., 22:77887.

26. Chan HL, de Silva HJ, Leung NW, Lim SG, Farrell GC; AsiaPacific Working Party on NAFLD ( 2007): How should we manage patients with nonalcoholic fatty liver disease in 2007? J. Gastroenterol .Hepatol. ,22(6):801-8.

27. Savery muttu S.H., Joseph A.E., Maxwell J.D. (1986): Ultrasound scanning in the detection of hepatic fibrosis and steatosis. BMJ; 292: 13-15

28. Maffei M., Halaas J., Ravussin E., Partly R.E., Lee G.H.,
Zhang Y., Fei H., Kim S., Lallone R., Ranganathan S., Kern P.A., and Freidman J.M. (1995): Leptin levels in human and rodent: measurement of plasma leptin and ob RNA in obese and weight-reduced subjects. Nature Med., 1: 11551161.

29. Stejskal D., Bartek J., Ruzicka V., Stejskal P., Jedelsky L., Oral I., Horalik D., Zurek M . (1999): Determination of leptin receptor in the serum and relations to laboratory and anthropological parameters in patients with atherosclerotic complications. Acta. Univ. Palacki .Olomouc Fac. Med., 142:89-92.

30. Bell G.I., Pictet R.L., et al., (1980): Sequence of the human insulin gene. Nature 284: 26-32, $P$

31. Inckard J.K., Sheehan K.C.F., and Schreiber R.D. (1997): Ligand induced formation of p55 and p75 tumor necrosis factor receptor heterocomplexes on intact cells. J. Biol. Chem. ,272, 10784-10789.

32. Arita Y., Kihara S., Ouchi N., Takahashi M. (1999) :Paradoxical decrease of an adipose-specific protein, adiponectin, in obesity. Biochem. Biophys. Res. Commun., 257(1): 79-83.

33. Matthews D.R., Hosker J.P., Rudenski A.S., Naylor B.A., Treacher D.F., Turner R.C. (1985): Homeostasis model assessment: insulin resistance and beta-cell function from fasting plasma glucose and insulin 
concentrations in man.

Diabetologia 28:412-419.

34. Tsochatzis E., Papatheodoridis G.V., Manesis E.K., Kafiri G., Tiniakos D.G., Archimandritis A.J. (2008): Metabolic syndrome is associated with severe fibrosis in chronic viral hepatitis and nonalcoholic steatohepatitis. Aliment. Pharmacol .Ther., 1;27(1):80-9.

35. Marchesini G., Forlani G. (2002): NASH: from liver diseases to metabolic disorders and back to clinical hepatology. Hepatology., 35:497-499.

36. Hjelkrem M.C., Torres D.M., Harrison S.A - (2008): Non alcoholic fatty liver disease. Minerva Med., 99(6):583-93.

37. Sanyal A.J. (2005): Mechanisms of Disease: pathogenesis of nonalcoholic fatty liver disease. Nat .Clin .Pract. Gastroenterol .Hepatol., 2(1):46-53.

38. Wellen K.E., Hotamisligil G.S. (2005): Inflammation, stress, and diabetes. J. Clin. Invest.,115(5):1111-9.

39. Gabriely I., Barzilai N. (2003): Surgical removal of visceral adipose tissue: effects on insulin action. Curr. Diab. Rep., 3(3):201-6.

40. Fuentes L., Roszer T., Ricote M. (2010): Inflammatory mediators and insulin resistance in obesity: role of nuclear receptor signaling in macrophages. Mediators Inflamm., 2010: 219583-219593.

41. Rocha R., Cotrim H.P., Carvalho F.M., Siqueira A.C., Braga H., and Freitas L.A. (2005): Body mass index and waist circumference in non- alcoholic fatty liver disease $\mathrm{J}$. Hum. Nutr. Diet., 18 (5): 365-70.

42. Fabbrini E., Sullivan S., Klein $S$ - (2009) :Obesity and nonalcoholic fatty liver disease: biochemical, metabolic, and clinical implications. Hepatology. , 51(2):679-89.

43. Huang X.D., Fan Y., Zhang H., Wang P., Yuan J.P., Li M.J., Zhan X.Y. (2008): Serum leptin and soluble leptin receptor in non-alcoholic fatty liver disease. World J. Gastroenterol. ,14(18):2888-93.

44. Krawczyk K., Szczesniak P., Kumor A., Jasinska A., et al., (2009): Adipohormones as prognostic markers in patients with nonalcoholic steatohepatitis (NASH). J .Physiol. Pharmacol., 60 Suppl 3:71-5.

45. Uygun A., Kadayifci A., Yesilova Z., Erdil A., et al., (2000): Serum leptin levels in patients with nonalcoholic steatohepatitis. Am. J. Gastroenterol., 95:3584-3588.

46. Tsochatzis E., Papatheodoridis G.V., Archimandritis A.J. (2006): The evolving role of leptin and adiponectin in chronic liver diseases. Am. J. Gastroenterol., 101(11):2629-40.

47. Ogawa T., Hirose H., Yamamoto Y. (2004): Relationships between serum soluble leptin receptor level and serum leptin and adiponectin levels, insulin resistance index, lipid profile, and leptin receptor gene polymorphisms in the Japanese population. Metabolism., 53(7):879-85. 
49. Zastrow O., Seidel B., Kiess W., Thiery J., et al., (2003): The soluble leptin receptor is crucial for leptin action: evidence from clinical and experimental data. Int .J .Obes. Relat. Metab .Disord. , 27(12):1472-8.

50. Paschos P., Paletas K. (2009): Non alcoholic fatty liver disease and metabolic syndrome. Hippokratia 13(1):9-19.

51. Xu H., Uysal K.T., Becherer J.D., et al. (2002): Altered tumor necrosis factor-alpha (TNF-alpha) processing in adipocytes and increased expression of transmembrane TNF-alpha in obesity. Diabetes 51:1876-83.

52. Valenti L., Fracanzani A.L., Dongiovanni P., et al. (2002): Tumor necrosis factor-alpha promoter polymorphisms and insulin resistance in nonalcoholic fatty liver disease. Gastroenterology 122:274-80.

53. Nguyen M.T., Satoh H., Favelyukis S., et al. (2005): JNK and tumor necrosis factor-alpha mediate free fatty acid-induced insulin resistance in 3T3-L1 adipocytes. J. Biol .Chem., 280:35361-71.

54. López-Bermejo A., Botas P., Funahashi T., Delgado E., Kihara S., Ricart W., Fernández-Real J.M. (2004): Adiponectin, hepatocellular dysfunction and insulin
sensitivity.Clin. Endocrinol., (Oxf). Feb; 60(2):256-63.

55. Bergman R.N., Kim S.P., Hsu I.R., Catalano K.J., Chiu J.D., Kabir M., Richey J.M., Ader M. (2007): Abdominal obesity: role in the pathophysiology of metabolic disease and cardiovascular risk. Am. J. Med., 120(2A): S3-S8.

56. Savvidou S., Hytiroglou P., Orfanou-Koumerkeridou H., Panderis A., Frantzoulis P., Goulis J. (2009): Low serum adiponectin levels are predictive of advanced hepatic fibrosis in patients with NAFLD. J. Clin. Gastroenterol.,43:765-772.

57. Jou J., Choi S.S., Diehl A.M. (2008): Mechanisms of disease progression in nonalcoholic fatty liver disease. Semin. Liver Dis., 28(4):370-9.

58. Shimada M., Kawahara H., Ozaki K., et al. (2007): Usefulness of a combined evaluation of the serum adiponectin level, HOMA-IR, and serum type IV collagen 7S level to predict the early stage of nonalcoholic steatohepatitis. Am. J.Gastroenterol., 102: 1931-1938.

59. Balmer M.L., Joneli J., Schoepfer A. et al., (2010): Significance of serum adiponectin levels in patients with chronic liver disease. Clinical Science 119: 431-436 


\section{الاديبوكينات ومرض التدهن الكبدى الغير كحولى}

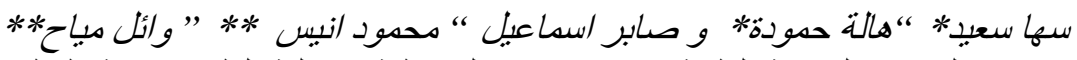
اقسام الكيمياء الحيوية الطبية* و الامر اض المنوطنة** كلية الطب جامعة طنطا

المقدمة: هناك زياده ملحوظه فى نسبة مرض تلدهن الكن الكبد الغير كحولى و غير واضح سببب حدوث زيادة دهون

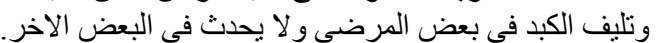

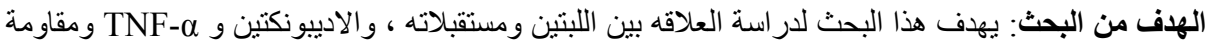

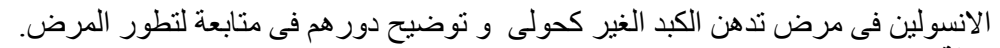

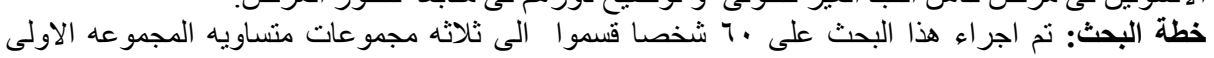

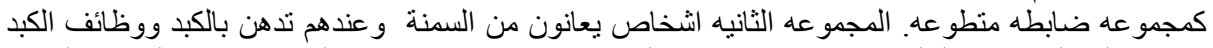

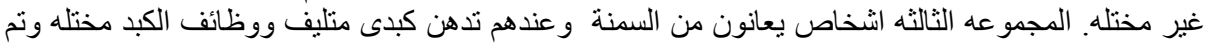

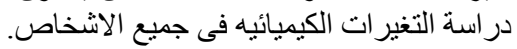

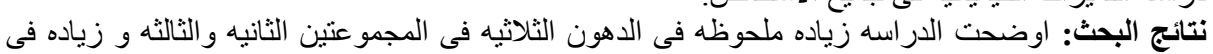

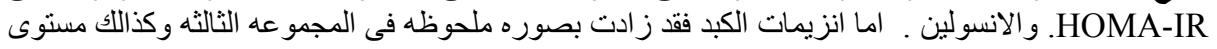

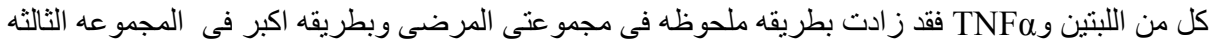

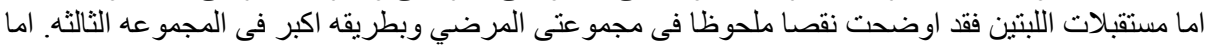

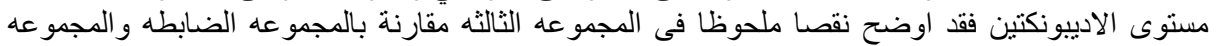

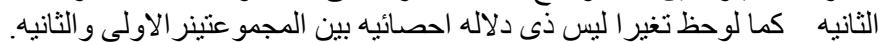

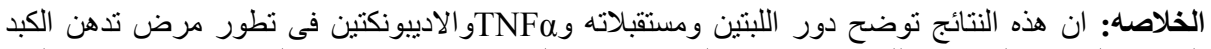

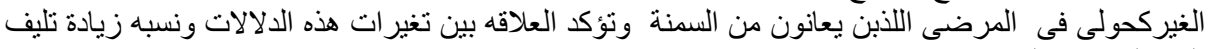

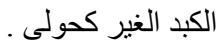

